\title{
A produção de alimentos e o problema da segurança alimentar
}

JOSÉ JULIANO DE CARVALHO FILHO

$\mathrm{O}$

TRABALHO DE HOFFMANN (1994), A insegurança alimentar no Brasil, evidencia que "o problema da fome no Brasil não se deve à pouca disponibilidade global de alimentos, mas sim à pobreza de grande parte da população". No texto, o autor também afirma que as políticas de combate à fome deverão ter como tônica o fortalecimento dos direitos (entitlements) dos pobres. Ou seja, o problema da fome no Brasil não é, primordialmente, uma questão de oferta, mas, basicamente, de demanda, dada a enorme desigualdade existente no país e a conseqüente marginalização de grande parte da população.

Embora concordemos com este posicionamento que enfatiza o lado da demanda, ou seja, da renda, existem questóes ligadas à oferta de alimentos relevantes para o debate sobre a segurança alimentar.

$\mathrm{O}$ intuito destas notas é discutir algumas destas questốes. Assim, neste texto abordam-se os seguintes aspectos da produção agrícola no Brasil: a segunda parte trata do comportamento da oferta agrícola em geral, com destaque para a oferta e para a disponibilidade per capita de alimentos; a terceira é dedicada ao estudo de cenários sobre a demanda de alimentos e perfil da oferta; por fim, a quarta parte apresenta a conclusão geral sobre a oferta de alimentos e acrescenta algumas observaçóes sobre o tema.

Oferta de alimentos no Brasil:

desempenho e previsóes

Comportamento da oferta agricola no Brasil:

capacidade de resposta cos pregos e transformaçōes

A indagação sobre a capacidade de resposta da oferta agrícola aos preços no Brasil é uma velha questáo, muito em voga na década dos 50 e na primeira metade dos anos 60. 
$\mathrm{Na}$ época, discutia-se a hipótese da inelasticidade preço da oferta, decorrente da estrutura fundiária caracterizada por forte concentração e predominância do latifúndio improdutivo e do minifúndio de subsistência. As interpretações marxista e estruturalista, embora por razões diferentes, propugnavam romper tal situação através de uma reforma agrária que, gerando grande número de pequenos proprietários, propiciaria a continuidade do desenvolvimento industrial. Dessa forma, tanto garantir-se-ia mercado para os bens produzidos pela indústria, como possibilitar-se-ia uma resposta adequada da oferta - principalmente de alimentos - às necessidades do processo de desenvolvimento, reduzindo-se as pressões inflacionárias.

Como é sabido, o tema provocou grande polêmica e suscitou uma série de pesquisas que buscou testar a hipótese da inelasticidade. Os resultados obtidos mostraram a não constatação de evidências empíricas para a sustentação da hipótese. Em suma, as exidências obtidas por Barbosa \& Santiago (1992) e Pastore (1968), autores que estudaram o tema, indicaram que a agricultura brasileira tem adequada capacidade de resposta aos estímulos do mercado.

Além da colocação sobre a capacidade de resposta da oferta agrícola, parece-nos interessante evidenciar que a agricultura brasileira, nas três últimas décadas, experimentou forte processo de transformação. Este processo, conhecido na literatura como modernização conservadora, embora excludente e concentrador, provocou expressivos e positivos resultados nos campos da produção e da agroindustrialização, resultando na mudança do padrão extensivo tradicional para um novo padrão intensivo, no qual o rendimento (produtividade da área) tornou-se a principal fonte de crescimento, superando a área cultivada.

A respeito, Alves \& Contini (1992), considerando dados para as 15 principais culturas no período $1940 / 50$ a 1970/80, mostram que o crescimento da produção, nas quatro décadas estudadas, foi expressivo e superior ao crescimento da população; evidenciam também, considerando as fontes de crescimento da produção, que a participação da produtividade da área foi modesta na primeira década (1940/50,17\%), acelerou-se nas seguintes (1950/60, 27,5\%; 1960/70, $35,3 \%)$, tornando-se o principal fator explicativo na última (1970/80, 59,3\%).

Considerando-se especificamente a década atual, informaçóes obtidas junto à Conab sobre a evolução da área plantada e produção mostram queda da área e oscilações, com tendência a crescimento, da produção. A safra 87/88 correspondeu a 42,8 milhóes de hectares plantados para uma produção em torno de 66 milhões de toneladas de grãos, enquanto a safra de 93/94 ocupou uma área de 36 milhões de hectares e atingiu 75 milhões de toneladas. Tais evidências permitem afirmar que a simples utilização da área anteriormente plantada implicaria expressivo aumento da produção. 
Outra colocação que julgamos relevante refere-se à consolidação da estrutura agroindustrial do país ter implicado fortes alterações na estrutura empresarial, apropriação de novas tecnologias e substituição de produtos alimentares tradicionais. Do lado da oferta, acelerou-se a participação de produtos destinados ao processamento agroindustrial, enquanto do lado da demanda ocorreu significativa diversificação da pauta de produtos e crescimento da participação de produtos com elevado grau de processamento industrial.

\section{Comportamento da oferta de alimentos}

A literatura que acompanha a oferta de alimentos no país, nas três últimas décadas, retrata comportamento em que as previsões pessimistas efetuadas no fim da década dos anos 70 não se concretizarão e, ao mesmo tempo, situação atual caracterizada por estagnação preocupante no que diz respeito ao nível de equilíbrio entre oferta e demanda.

Tabela 1

Taxas de crescimento médio anual das quantidades produzidas e dos rendimentos físicos de lavouras selecionadas $1961 / 70$ e $1971 / 80$

(em \%)

\begin{tabular}{lrrrr}
\hline \multicolumn{2}{l}{$\begin{array}{l}\text { Q Quantidades } \\
\text { produzidas } \\
\text { selecionadas }\end{array}$} & \multicolumn{3}{c}{$\begin{array}{c}\text { Rendimentos } \\
\text { físicos }\end{array}$} \\
& $1961 / 70$ & $1971 / 80$ & $1961 / 70$ & $1971 / 80$ \\
\hline Produtos exportáveis & & & & \\
& & & & \\
Soja & 17,9 & 18,6 & 0,8 & 1,1 \\
Laranja & 6,1 & 11,8 & 0,7 & 3,0 \\
Açúcar & 3,2 & 7,0 & 0,9 & 2,4 \\
Fumo & 4,2 & 6,8 & 3,0 & 2,7 \\
Cacau & 3,6 & 5,6 & $-1,9$ & $-2,6$ \\
Café & $-9,1$ & $-3,1$ & 4,6 & 5,2 \\
Algodão & 0,8 & $-4,8$ & $-1,4$ & $-3,0$ \\
& & & - & - \\
Produtos de consumo interno & & & & \\
& & & & \\
Trigo & 11,8 & 6,9 & 2,0 & 1,1 \\
Milho & 4,8 & 2,6 & $-1,5$ & $-0,3$ \\
Arroz & 2,8 & 2,7 & $-0,3$ & $-4,6$ \\
Mandioca & 5,5 & $-2,2$ & 0,9 & 1,3 \\
Feijão & 3,5 & $-2,7$ & 1,2 & $-2,4$ \\
\hline
\end{tabular}

Fonte: Ibge

Nota: As táxas acima foram obtidas por ajuste exponencial. 
Ao considerarmos os dados referentes às décadas de 60 e 70 (tabela 1), verificamos, como afirmam Goldin \& Resende (1993), que "o fim da década de 60 e o começo da década de 70 marcaram uma reversão do equilíbrio entre o crescimento da agricultura para o mercado interno e o da agricultura de exportação. Ėntre uma década e outra, acelerou-se o crescimento da produção de lavouras de exportação, enquanto caiu o ritmo de crescimento da produção de culturas alimentares. Dentre estas, apenas o trigo teve crescimento significativo da produção per capita nos anos 70".

A literatura da época registrava queda da produçáoper capita de produtos alimentares. Recente trabalho de Homem de Melo (1994), comentando o bom desempenho da oferta agrícola global para o período 1952/92, relembra a ocorrência do fato para os anos $70 \mathrm{e}$ início dos $\mathbf{8 0}$. Exemplificando, o autor mostra que entre 1977 e 1984 ocorreu redução de $12,8 \%$ na produção total per capita de arroz, feijão, milho, mandioca e.batata.

As análises efetuadas na época indicavam que, no período, o crescimento agrícola foi liderado pelas exportaçóes em detrimento das culturas alimentares. As previsões que então se faziam eram pessimistas. Principalmente, supunha-se que a crise do balanço de pagamentos forçaria o governo a conceder maiores incentivos às culturas de exportação e à produção de cana-de-açúcar para fins energéticos, o que agravaria o problema da produção de alimentos (Goldin \& Resende, 1993:71).

Os fatos não confirmaram as previsóes pessimistas. Goldin \& Resende (1993:71), comentando a tabela 2, que apresenta as taxas de crescimento anual da produção e dos rendimentos físicos de lavouras selecionadas, mostram que "a produção agrícola vegetal de mercado interno aumentou a sua taxa de crescimento na década de 80, em comparaçáo com a de 70". Os autores prosseguem afirmando que "se pode observar um nítido aumento da taxa de crescimento da produção de arroz, milho e trigo no período mais recente. Por outro lado, boa parte desse aumento deveu-se à evoluçáo mais favorável dos rendimentos físicos (...), com contribuição pequena, ou até mesmo negativa, da expansão da área".

Os trabalhos que procuraram explicar o bom desempenho da agricultura de consumo interno na década de 80 apontaram, como sua causa, a implementação de uma política agrícola que estimulou as culturas de mercado interno, principalmente via mudanças no programa de preços mínimos. As alteraçóes nesse programa protegeram os produtores agrícolas dos efeitos do aperto do crédito rural, concretizado na segunda metade dos anos $\mathbf{8 0}$.

Além deste registro sobre a recuperação das lavouras alimentares nos anos 
80, acreditamos relevante para os objetivos propostos neste texto atualizar as informações sobre algumas culturas importantes para o abastecimento alimentar, bem como analisar as estimativas disponíveis sobre a disponibilidade per capita dos alimentos.

\section{Tabela 2}

Brasil - Taxa de crescimento anual da produção e dos rendimentos

de lavouras selecionadas

$1973 / 81$ e 1979/89

$(\mathrm{em} \%)$

Produtos

Taxas de Crescimento Anual

$1973 / 81$

$1979 / 89$

\begin{tabular}{|c|c|c|}
\hline \multicolumn{3}{|l|}{ Arroz } \\
\hline Producão & $1,5^{*}$ & 3,2 \\
\hline Rendimento físico & $-0,9$ & 3,9 \\
\hline \multicolumn{3}{|l|}{ Feijão } \\
\hline Produção & $-0,3^{*}$ & $0,6^{\star}$ \\
\hline Rendimento físico & $-2,3$ & $-1,0$ \\
\hline \multicolumn{3}{|l|}{ Mandioca } \\
\hline \multicolumn{3}{|c|}{ Produção $-0,9-0,3^{*}$} \\
\hline \multicolumn{3}{|c|}{ Rendimento físico $-1,21,1$} \\
\hline \multicolumn{3}{|l|}{ Milho } \\
\hline Produção & $2,0^{*}$ & 3,1 \\
\hline Rendimento físico & $0,8^{*}$ & 1,4 \\
\hline \multicolumn{3}{|l|}{ Trigo } \\
\hline Produção & $2,4^{*}$ & 14,2 \\
\hline Rendimento físico & $-0,5^{*}$ & 9,9 \\
\hline \multicolumn{3}{|l|}{ Algodão } \\
\hline Produção & $-1,3^{*}$ & 3,3 \\
\hline Rendimento físico & $-0,4^{*}$ & 8,7 \\
\hline \multicolumn{3}{|l|}{ Cana-de-açúcar } \\
\hline Produção & 8,3 & 8,6 \\
\hline Rendimento físico & 3,3 & 1,3 \\
\hline \multicolumn{3}{|l|}{ Soja } \\
\hline Produção & 7,3 & 3,7 \\
\hline Rendimento físico & $-1,9^{*}$ & $1,0^{*}$ \\
\hline
\end{tabular}

Nota: Todas as taxas foram obtidas por ajustamento exponencial das quantidades produzidas e dos rendimentos físicos, com os dados originais transformados em médias móveis trienais. Os coeficientes assinalados com (*) não são significativamente diferentes de zero em nivel de $5 \%$ (teste de tbicaudal). 
Para tanto, destacaremos alguns trabalhos recentes dedicados ao tema, como o ensaio da Conab (Embrapa, 1989) dedicado à problemática atual da agricultura e à apresentação de proposta de política adaptada às necessidades atuais; trabalhos desenvolvidos no Instituto de Economia Agrícola, órgáo da Secretaria da Agricultura e Abastecimento do Estado de São Paulo, voltados para o cálculo da disponibilidade per capita de proteínas e calorias (1); e as contribuiçóes de Veiga (1994) sobre a questão dos preços dos produtos alimentícios.

Tabela 3

Exportação e importações de grãos

Produto (em mil t)

\begin{tabular}{|c|c|c|c|c|c|c|c|c|}
\hline \multirow{2}{*}{$\begin{array}{l}\text { Médias } \\
\text { anuais }\end{array}$} & \multicolumn{2}{|c|}{ Algodão } & \multicolumn{2}{|c|}{ Arroz } & \multicolumn{2}{|c|}{ Feijão } & \multicolumn{2}{|c|}{ Milho } \\
\hline & Imp. & Exp. & Imp. & Exp. & Imp. & Exp. & Imp. & Exp. \\
\hline $\begin{array}{l}1987 / 90 \\
1991 / 94\end{array}$ & $\begin{array}{r}78,0 \\
300,0\end{array}$ & $\begin{array}{r}120,0 \\
45,0\end{array}$ & $\begin{array}{l}349,0 \\
940,0\end{array}$ & $\begin{array}{l}9,0 \\
2,0\end{array}$ & $\begin{array}{l}35,0 \\
71,0\end{array}$ & - & $\begin{array}{l}435,0 \\
498,0\end{array}$ & - \\
\hline \multirow{2}{*}{$\begin{array}{l}\text { Médias } \\
\text { anuais }\end{array}$} & \multicolumn{2}{|c|}{ Trigo } & \multicolumn{4}{|c|}{$\begin{array}{l}\text { Soja } \\
\text { Exportações Líquidas }\end{array}$} & & \\
\hline & Imp. & Exp. & & Grão & Oleo & Farelo & & \\
\hline $\begin{array}{l}1987 / 90 \\
1991 / 94\end{array}$ & $\begin{array}{l}1.816,0 \\
4.643,0\end{array}$ & - & & $\begin{array}{l}3.458 \\
3.582\end{array}$ & $\begin{array}{l}801 \\
665\end{array}$ & $\begin{array}{l}8.827 \\
8.865\end{array}$ & & \\
\hline \multirow{2}{*}{$\begin{array}{l}\text { Médias } \\
\text { anuais }\end{array}$} & \multicolumn{2}{|c|}{ Algodão } & \multicolumn{2}{|c|}{ Arroz } & \multicolumn{2}{|c|}{ Feijão } & \multicolumn{2}{|c|}{ Milho } \\
\hline & Imp. & Exp. & Imp. & Exp & $\operatorname{Imp}$ & Exp & $\operatorname{Imp}$ & Exp. \\
\hline $\begin{array}{l}1987 / 90 \\
1991 / 94\end{array}$ & $\begin{array}{r}78,0 \\
300,0\end{array}$ & $\begin{array}{r}120,0 \\
45,0\end{array}$ & $\begin{array}{l}349,0 \\
940,0\end{array}$ & $\begin{array}{l}9,0 \\
2,0\end{array}$ & $\begin{array}{l}35,0 \\
71,0\end{array}$ & $\overline{-}$ & $\begin{array}{l}435,0 \\
498,0\end{array}$ & - \\
\hline \multirow[b]{2}{*}{$\begin{array}{l}\text { Médias } \\
\text { anuais }\end{array}$} & \multicolumn{2}{|c|}{ Trigo } & \multicolumn{4}{|c|}{$\begin{array}{c}\text { Soja } \\
\text { Exportações Líquidas }\end{array}$} & 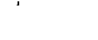 & \\
\hline & Imp. & Exp. & & $\begin{array}{l}\text { Exp } \\
\text { Grão }\end{array}$ & $\begin{array}{l}\text { Çóes L } \\
\text { Óleo }\end{array}$ & $\begin{array}{l}\text { lidas } \\
\text { Farelo }\end{array}$ & & \\
\hline $\begin{array}{l}1987 / 90 \\
1991 / 94\end{array}$ & $\begin{array}{l}1.816,0 \\
4.643,0\end{array}$ & - & & $\begin{array}{l}3.458 \\
3.582\end{array}$ & $\begin{array}{l}801 \\
665\end{array}$ & $\begin{array}{l}8.827 \\
8.865\end{array}$ & & \\
\hline
\end{tabular}

Fonte: Conab/Dipla

O trabalho da Conab apresenta como evidências da situaçáo atual a ocorrência de comportamento bastante irregular da produção total de grãos nas últimas safras, com tendência de pequeno crescimento; a disponibilidade per capita de todos os grãos situando-se no mesmo nível de uma década atrás; e o abastecimento interno de grãos cada vez mais dependente das importaçốes.

A evidência sobre a crescente dependência do abastecimento para com o comércio exterior é importante e precisa ser melhor analisada. Posteriormente, abordaremos a questáo da disponibilidade per capita. Quanto à irregularidade na produção de grãos, o que já foi dito sobre o comportamento da produção, somado às estatísticas a serem ainda comentadas neste trabalho, confirmam o fato. 


\section{Abastecimento e dependência externa}

A respeito da crescente dependência externa do abastecimento, com base na tabela 3, o citado ensaio da Conab destaca que as estatísticas de comércio exterior de grãos, para os últimos oito anos, retratam "expressivo crescimento nas importações de alimentos sem que tivesse sido registrado um aumento significativo nas exportaçóes”.

Embora os números apresentados na tabela 3 sejam claros quanto ao aumento das importaçōes, acreditamos que se fazem necessárias algumas qualificaçóes para melhor esclarecer sobre o suprimento de produtos considerados básicos para a alimentação.

Utilizando a tabela fornecida pela própria Conab (tabela 4 - Oferta e demanda internas e externas, aqui dividida por produto) elaboramos algumas observaçōes para quatro produtos selecionados (trigo, feijão, arroz e milho).

Tabela 4

a) Trigo

(Em $1000 t)$

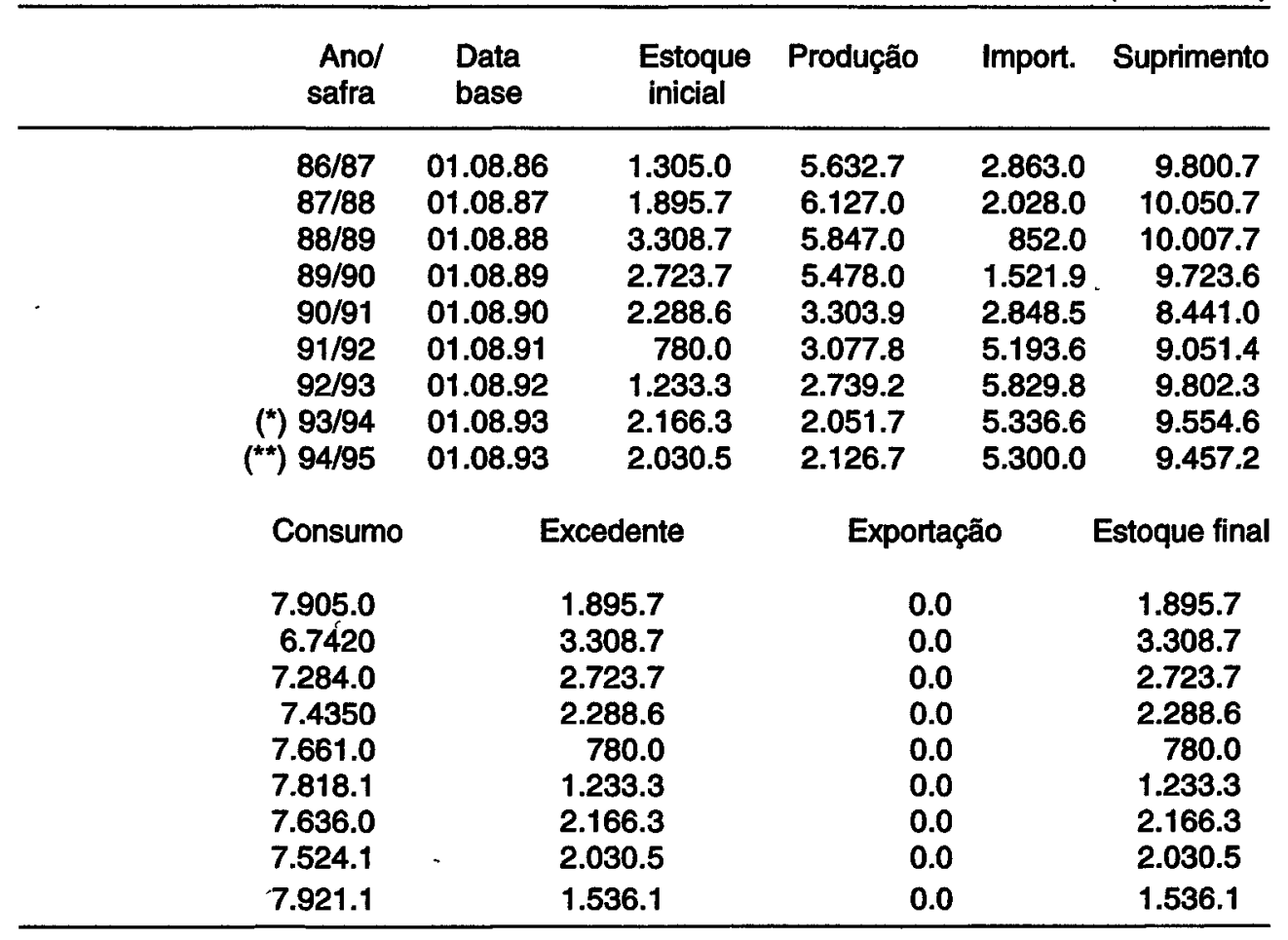

(*) Dados Preliminares

(*) Projeção

Fonte: Conab/Dipla 
Para o caso do trigo (tabela 4a), o consumo aparente total permanece praticamente constante para as últimas nove safras (em torno de 7.500 mil t $)$. O seu maior nível corresponde à estimativa para a safra $94 / 95(7.921,1$ mil t $)$, que é praticamente igual ao nível da safra 86/87. A produção apresenta grande queda a partir da safra 88/ 89, que correspondeu a 5.847 mil t, enquanto a safra de 94/95 apresenta estimativa de $2.126,7$ mil t. As importaçóes apresentam grande salto, especialmente a partir da safra $91 / 92$, situando-se em torno de $\mathbf{5 . 5 0 0}$ mil t. Tal comportamento é explicável pela queda da política de subsídios e condiçóes do mercado mundial. $O$ trigo nacional năo é competitivo e o abastecimento deverá manter a dependência para com $o$ produto estrangeiro, principalmente do Mercosul, de origem argentina.

b) Feijão

Tabela 4 (continuação)

\begin{tabular}{|c|c|c|c|c|c|c|}
\hline & $\begin{array}{l}\text { Ano/ } \\
\text { Safra }\end{array}$ & $\begin{array}{l}\text { Data } \\
\text { Base }\end{array}$ & $\begin{array}{l}\text { Estoque } \\
\text { Inicial }\end{array}$ & Produção & Import & Suprimento \\
\hline & $\begin{array}{r}82 / 83 \\
83 / 84 \\
84 / 85 \\
85 / 86 \\
86 / 87 \\
87 / 88 \\
88 / 89 \\
89 / 90 \\
90 / 91 \\
91 / 92 \\
\left({ }^{*}\right) 92 / 93 \\
\left({ }^{* *}\right) 93 / 94\end{array}$ & $\begin{array}{l}01.11 .82 \\
01.11 .83 \\
01.11 .84 \\
01.11 .85 \\
01.11 .86 \\
01.11 .87 \\
01.11 .88 \\
01.11 .89 \\
01.11 .90 \\
01.11 .91 \\
01.11 .92 \\
01.11 .94\end{array}$ & $\begin{array}{r}655.5 \\
222.4 \\
169.9 \\
332.0 \\
267.2 \\
100.3 \\
265.3 \\
76.7 \\
116.1 \\
372.8 \\
537.3 \\
199.5\end{array}$ & $\begin{array}{l}1.654 .7 \\
2.616 .1 \\
2.534 .7 \\
2.224 .8 \\
2.108 .0 \\
2.752 .0 \\
2.386 .4 \\
2.339 .9 \\
2.806 .2 \\
2.902 .4 \\
2.402 .9 \\
3.123 .1\end{array}$ & $\begin{array}{r}3.7 \\
60.5 \\
15.3 \\
95.0 \\
35.0 \\
10.0 \\
25.0 \\
70.3 \\
88.6 \\
57.7 \\
54.9 \\
42.0\end{array}$ & $\begin{array}{l}2.313 .9 \\
2.899 .0 \\
2.719 .9 \\
2.671 .8 \\
2.410 .2 \\
2.868 .3 \\
2.676 .7 \\
2.486 .9 \\
3.010 .9 \\
3.332 .9 \\
2.995 .1 \\
3.364 .6\end{array}$ \\
\hline & Consumo & & Excedente & Exportação & & Estoque final \\
\hline$\cdot$ & $\begin{array}{l}2.076 .6 \\
2.723 .5 \\
2.378 .2 \\
2.400 .0 \\
2.300 .0 \\
2.600 .0 \\
2.600 .0 \\
2.370 .8 \\
2.638 .1 \\
2.795 .6 \\
2.795 .6 \\
2.921 .4\end{array}$ & & $\begin{array}{r}237.3 \\
175.5 \\
341.7 \\
271.8 \\
110.2 \\
268.3 \\
76.7 \\
116.1 \\
372.8 \\
537.3 \\
199.5 \\
443.2\end{array}$ & $\begin{array}{r}14.9 \\
5.6 \\
9.7 \\
4.6 \\
3.9 \\
3.0 \\
0.0 \\
0.0 \\
0.0 \\
0.0 \\
0.0 \\
0.0\end{array}$ & , & $\begin{array}{r}222.4 \\
169.9 \\
332.0 \\
267.2 \\
106.3 \\
265.3 \\
76.7 \\
116.1 \\
372.8 \\
537.3 \\
199.5 \\
443.2\end{array}$ \\
\hline
\end{tabular}

(") Dados preliminares

(**) Projeção

Fonte: Conab/Dipla

No caso do feijão (tabela 4b), o consumo aparente total não apresenta alteraçóes significativas. Verifica-se pequena recuperação para as últimas três safras (91/92 a 93/94, esta com 2.921,4 mil t). Todavia, o nível do consumo para as safras 91/92 e 
92/93 é pouco superior ao consumo aparente correspondente à safra 83/84 (respectivamente, $2.795,6$ mil t e $2.723,5 \mathrm{mil}$ t). A produção para as últimas sete safras oscila em torno de 2.674 mil t, com melhor desempenho para 93/94 (projeçáo de $3.123,1 \mathrm{mil} t$ ). As importações apresentam comportamento oscilante para todo o período (82/83 a 93/94), não se verificando tendência de crescimento. As maiores importaçóes ocorreram nas safras 90/91 (88,6 mil t) e 85/86 (95 mil t ). Para as três safras seguintes o seu comportamento é de declínio, atingindo 42 mil t em 93/94. Cabe aqui observar que o montante das importaçōes para as três últimas safras corresponde a $1,81 \%$ do consumo e $1,60 \%$ do suprimento, não sendo portanto significativa. Além disso, tradicionalmente ocorre importação de caráter complementar de feijão preto argentino.

Tabela 4 (continuação)

c) Arroz em casca

(Em $1.000 t)$

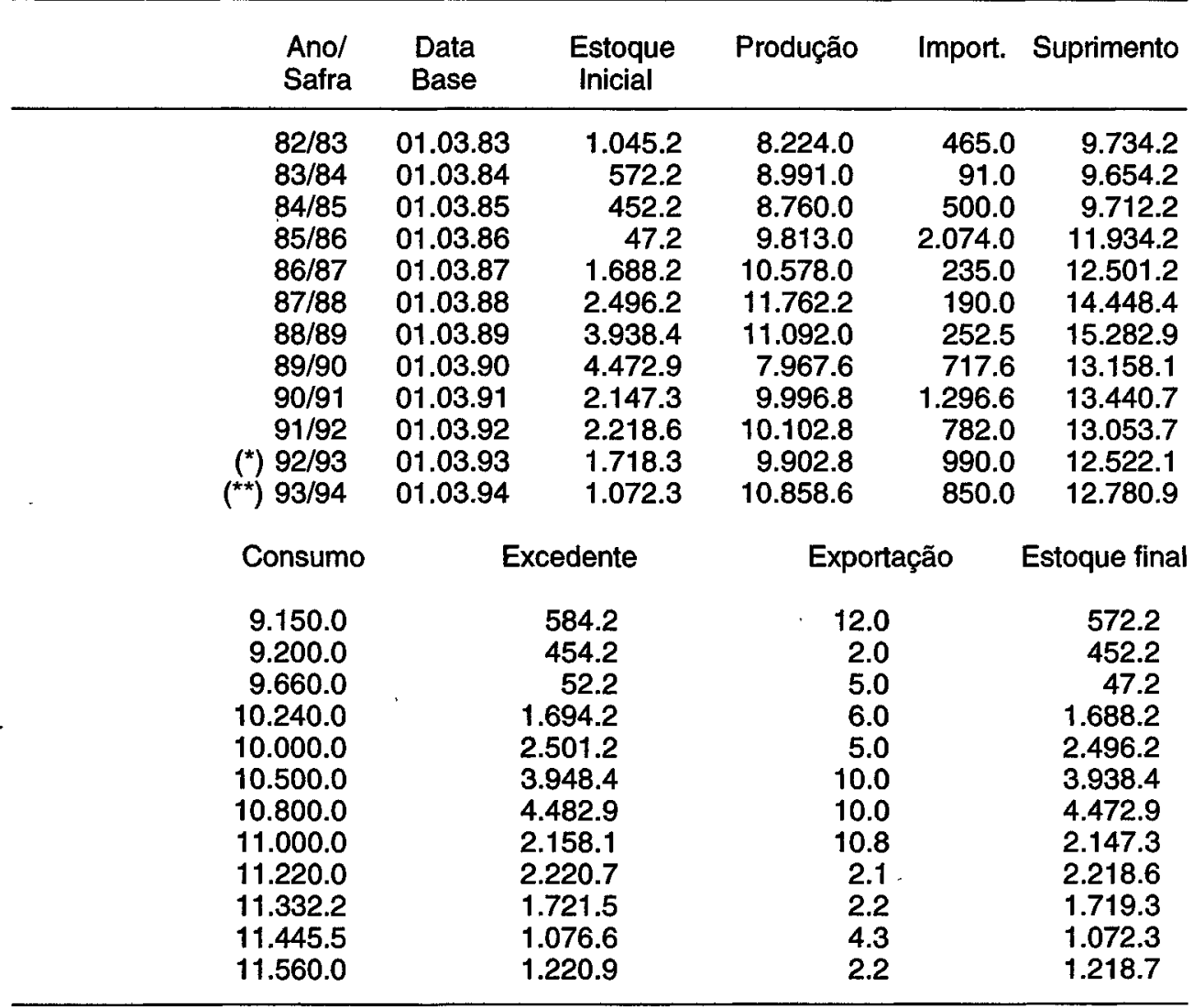

(*) Dados Preliminares

(**) Projeção

Fonte: Conab/Dipla

O arroz (tabela 4c) apresenta situação com algumas características importantes. O consumo aparente total mostra-se crescente para o período compreendido pelas safras $82 / 83$ e $93 / 94$. Comparando a média das três primeiras safras $(9.336,6$ mil $t)$ com a média para as três últimas ( $11.445,9$ mil t $)$ verificamos acrésci- 
mo de $22,3 \%$. A produção apresenta comportamento com grandes oscilações, sem tendência a crescimento para as últimas oito safras. As importações também osci$\mathrm{lam}$, atingindo máximos de $2.074 \mathrm{mil} \mathrm{t} \mathrm{em} \mathrm{85/86} \mathrm{e} \mathrm{1.296,6} \mathrm{mil} \mathrm{t} \mathrm{em} \mathrm{90/91.} \mathrm{Con-}$ siderando as últimas cinco safras verificamos que as importações correspondem a 7,9\% do consumo, cabendo ainda ressaltar que para o mesmo período ocorre grande queda dos estoques. Este nível de importações não é desprezível. A respeito, é interessante acrescentarmos algumas informações colhidas junto à Conab. As áreas disponíveis de terras próprias para o plantio do arroz irrigado no Rio Grande do Sul, exigem significativos investimentos para serem produtivas. $\mathrm{O}$ arroz nacional, em grande parte, é fortemente onerado pelos custos excessivos do arrendamento de terras. O produto oriundo do Mercosul tem melhores condiçóes de competitividade. Além desses fatos, em determinadas épocas do ano, o produto de origem asiática apresenta alto grau de competitividade no mercado internacional. Esse conjunto de informaçóes nos levam a concluir que é de se esperar, para futuro próximo, o alargamento da participação do produtò estrangeiro (principalmente do Mercosul) no suprimento nacional, todavia sem asfixia da produção irrigada do país.

d) milho

Tabela 4 (continuação)

\begin{tabular}{|c|c|c|c|c|c|}
\hline $\begin{array}{l}\text { Anol } \\
\text { Safra }\end{array}$ & $\begin{array}{l}\text { Data } \\
\text { Base }\end{array}$ & $\begin{array}{l}\text { Estoque } \\
\text { Inicial }\end{array}$ & Produção & Import. & Suprimento \\
\hline $\begin{array}{r}82 / 83 \\
83 / 84 \\
84 / 85 \\
85 / 86 \\
86 / 87 \\
87 / 88 \\
88 / 89 \\
89 / 90 \\
90 / 91 \\
91 / 92 \\
\left(^{*}\right) 92 / 93 \\
\text { (**) }^{*} 93 / 94\end{array}$ & $\begin{array}{l}01.03 .83 \\
01.03 .84 \\
01.03 .85 \\
01.03 .86 \\
01.03 .87 \\
01.03 .88 \\
01.03 .89 \\
01.03 .90 \\
01.03 .91 \\
01.03 .92 \\
01.03 .93 \\
01.03 .94\end{array}$ & $\begin{array}{r}1.823 .4 \\
823.5 \\
2.121 .0 \\
600.0 \\
1.600 .1 \\
2.879 .4 \\
2.798 .0 \\
3.079 .7 \\
1.237 .4 \\
822.7 \\
3.433 .5 \\
3.058 .2\end{array}$ & $\begin{array}{l}19.014 .1 \\
21.177 .5 \\
21.173 .9 \\
20.264 .1 \\
26.758 .3 \\
25.223 .6 \\
26.266 .8 \\
22.257 .4 \\
24.041 .4 \\
30.770 .8 \\
29.179 .7 \\
32.046 .7\end{array}$ & $\begin{array}{r}213.1 \\
253.0 \\
262.1 \\
2.423 .6 \\
871.2 \\
15.0 \\
154.929 \\
700.0 \\
832.2 \\
340.0 \\
1.220 .0 \\
400.0\end{array}$ & $\begin{array}{r}21.050 .0 \\
22.254 .6 \\
23.557 .0 \\
23.287 .7 \\
29.229 .8 \\
28.118 .0 \\
219.7 \\
26.037 .1 \\
26.110 .7 \\
31.933 .5 \\
33.833 .2 \\
35.504 .9\end{array}$ \\
\hline Consumo & \multicolumn{2}{|c|}{ Excedente } & \multicolumn{2}{|c|}{ Exportação } & Estoque final \\
\hline $\begin{array}{l}19.464 .2 \\
19.955 .4 \\
22.957 .0 \\
21.687 .6 \\
20.350 .2 \\
25.320 .0 \\
26.140 .0 \\
24.800 .0 \\
25.288 .0 \\
28.500 .0 \\
30.775 .0 \\
32.732 .0\end{array}$ & \multicolumn{2}{|c|}{$\begin{array}{r}1.589 .4 \\
2.299 .2 \\
600.0 \\
1.600 .1 \\
2.879 .4 \\
2.798 .0 \\
3.079 .7 \\
1.237 .1 \\
822.7 \\
3.433 .5 \\
3.058 .2 \\
2.772 .9\end{array}$} & \multicolumn{2}{|c|}{$\begin{array}{r}765.9 \\
178.2 \\
0.0 \\
0.0 \\
0.0 \\
0.0 \\
0.0 \\
0.0 \\
0.0 \\
0.0 \\
0.0 \\
0.0\end{array}$} & $\begin{array}{r}828.5 \\
2.121 .0 \\
600.0 \\
1.600 .1 \\
2.879 .4 \\
2.798 .0 \\
3.079 .7 \\
1.237 .1 \\
822.7 \\
3.433 .5 \\
3.058 .2 \\
2.772 .9\end{array}$ \\
\hline
\end{tabular}

(*) Dados Preliminares

(**) Projeção

Fonte: Conab/Dipla 
Finalmente, para o caso do milho (tabela $4 \mathrm{~d}$ ) os dados da Conab mostram clara tendência de crescimento do consumo aparente, passando de 19.464,2 mil t na safra $82 / 83$, para 32.732 mil t na safra 93/94. A produção também apresenta a mesma tendência, embora com algumas oscilaçốes. Considerando as mesmas safras, os montantes produzidos são, respectivamente, 19.014,1 mil t e 32.046,7 mil t. As importaçôes são de caráter complementar, apresentando oscilaçóes mas não atingindo níveis expressivos. Considerando a série da Conab, notamos dois anos-safra com importaçóes excepcionais (2.423,6 mil t para 85/ 86 e 1.220 mil t em 92/93). Comparando o início da série (três safras), com as últimas cinco safras observamos valor maior para as importaçóes; todavia, como já afirmamos não chega a atingir níveis significativos. $O$ comportamento positivo do produto, tanto no que diz respeito à produçāo, quanto ao consumo, está relacionado com a produção de rações animais, especialmente no que tange à avicultura.

Dados os atuais padróes de consumo e as possibilidades de importaçóes, $o$ que inclui o advento do Mercosul, as análises apresentadas não configuraram qualquer situação de estrangulamento para o abastecimento interno referente aos grãos considerados. Para o feijão e o milho, a participação do comércio exterior não é significativa. Para o caso do trigo, o crescimento das exportações é explicável por condições de produção e de mercado. Finalmente, para o arroz, embora a análise indique a tendência para maior participação das importaçóes, não se pode prever problemas de desabastecimento, dadas as possibilidades do comércio exterior e provável realocação da produção na área do Mercosul.

\section{Disponibilidade per capita de alimentos}

As tabelas analisadas não permitem afirmativas sobre o que vem ocorrendo com a disponibilidade per capita de alimento. Todavia, a constância verificada nos níveis de consumo aparente para o feijăo e o trigo, e mesmo os valores relativos ao arroz para as últimas cinco safras, são indicativos de problemas quanto à disponibilidade per capita. A indicação é de possível queda ou estabilidade.

Para efeito de discussão junto ao Grupo de Trabalho sobre Segurança Alimentar do Instituto de Estudos Avançados da USP selecionamos algumas contribuições recentes sobre 0 assunto.

O primeiro trabalho considerado foi o de Almeida (1994). Analisando a tabela 5, na qual o autor apresenta dados sobre a disponibilidade interna de alimentos, verificamos que a tendência de redução da disponibilidade é clara apenas para o feijão e a mandioca. Para os casos de alho, arroz, batata e trigo, não é possível estabelecer tendências. Por outro lado, observamos aumento da disponibilidade para cebola, milho e tomate. 
Sobre os dados de Almeida, acresce ainda notarmos que as tendências claras de redução de disponibilidade ocorrem para produtos de baixa elasticidade renda (feijão e mandioca). Além deste fato, é importante também considerarmos que, pelo menos para o caso do feijão, a literatura tem registrado diminuiçáo de consumo conseqüiente das mudanças de hábitos alimentares da população (Hoffmann, 1994).

Tabela 5

Disponibilidade interna per capita/ano de alguns alimentos

(em kg)

\begin{tabular}{lrrrrr}
\hline & \multicolumn{5}{c}{ Ano } \\
Produto & 1960 & 1970 & 1980 & 1990 & $1994\left(^{*}\right)$ \\
\hline Alho & 0,38 & 0,395 & 0,339 & 0,493 & 0,386 \\
Arroz em casca & 68,31 & 81,094 & 82,147 & 55,303 & 71.539 \\
Cebola & 2,993 & 3,056 & 5,837 & 6,032 & 6,574 \\
Batata & 15,851 & 17,002 & 16,298 & 15,402 & 9,586 \\
Feijão & 24,658 & 24,817 & 16,747 & 16,275 & 14,586 \\
Mandioca & 250,093 & 316,347 & 197,186 & 168,560 & 156,074 \\
Milho & 123,547 & 152,632 & 171,189 & 155,183 & 190,056 \\
Tomate & 5,657 & 8,204 & 12,901 & 15,653 & 14,295 \\
Trigo & 10,159 & 20,233 & 22,702 & 22,932 & 14,161 \\
\hline
\end{tabular}

(*) estim.

Fonte dos dados brutos: Fibge - Faep/DTE, maio/94

Frente a essas constataçôes, somadas à evidência de que a pauta de produtos para o consumo vem passando por diversificação e diferenciação, procuramos estatísticas mais aproximadas da realidade atual.

Uma equipe de pesquisadores do Instituto de Economia Agrícola de São Paulo (vide nota 1) tem se dedicado à quantificação e análise de balanços da disponibilidade-consumo de alimentos no Brasil, calculando a disponibilidade de calorias e proteínas. Para tanto, a gama de produtos considerada como fontes calórica e protéica é bastante ampla (2) e incorpora, pelo menos em boa parte, a substituição entre as fontes. Dessa forma, tais dados mostram-se mais adequados para a análise da evolução da disponibilidade em questão.

As tabelas 6 e 7 resumem os resultados obtidos pelo Instituto de Economia Agrícola para a disponibilidade de alimentos (3).

Considerando a disponibilidade per capita/dia de calorias (tabela 6), notamos claramente comportamento de estabilidade para a última década - as variações são pouco significativas. $O$ valor mais alto atingido em 1980, nunca mais foi 
alcançado. Notamos também alguma redução da disponibilidade na primeira metade dos anos 80 , seguida de pequena recuperação. Os dados evidenciam a estagnação do consumo de calorias para os últimos 12 anos considerados na tabela.

Tabela 6

Total geral de calorias - Brasil 1970-92

(em bilhão calorias)

\begin{tabular}{|c|c|c|c|}
\hline \multirow[t]{2}{*}{ Ano } & \multirow{2}{*}{$\begin{array}{l}\text { Disponibilidade } \\
(\mathrm{O}-\mathrm{R})^{*}\end{array}$} & \multicolumn{2}{|c|}{ Disponibilidade per capita } \\
\hline & & $\mathrm{kcal} / \mathrm{ano}$ & kcal/dia \\
\hline 1970 & $67.058,27$ & 719980 & 1973 \\
\hline 1971 & $67.157,69$ & 703593 & 1928 \\
\hline 1972 & $60.703,00$ & 620574 & 1700 \\
\hline 1973 & $71.891,49$ & 717164 & 1965 \\
\hline 1974 & $73.266,30$ & 713185 & 1954 \\
\hline 1975 & $75.936,78$ & 721287 & 1976 \\
\hline 1976 & $92.523,83$ & 857564 & 2349 \\
\hline 1977 & $92.033,41$ & 832370 & 2280 \\
\hline 1978 & $96.783,73$ & 854143 & 2340 \\
\hline 1979 & $95.509,60$ & 822494 & 2253 \\
\hline 1980 & $109.453,04$ & 919753 & 2520 \\
\hline 1981 & $102.732,95$ & 846902 & 2320 \\
\hline 1982 & $108.120,98$ & 874407 & 2396 \\
\hline 1983 & $99.598,71$ & 790201 & 2165 \\
\hline 1984 & $108.203,26$ & 842180 & 2307 \\
\hline 1985 & $113.981,84$ & 870323 & 2384 \\
\hline 1986 & $119.625,39$ & 896083 & 2455 \\
\hline 1987 & $119.478,19$ & 877999 & 2405 \\
\hline 1988 & $117.798,20$ & 849228 & 2327 \\
\hline 1989 & $122.964,97$ & 869656 & 2383 \\
\hline 1990 & $108.102,55$ & 750036 & 2055 \\
\hline 1991 & $133.068,08$ & 905734 & 2481 \\
\hline 1992 & $133.970,06$ & 894571 & 2451 \\
\hline
\end{tabular}

(') (O-R) = Oferta (produção, importações) menos retirada (exportações, consumo animal, sementes, perdas) Fonte: CARVALHO, Flávio C. de. Disponibilidade de calorias e proteínas no Brasil: uma reavaliação das estatisticas para a década de oitenta. São Paulo, IEA, 1993.

Praticamente as mesmas conclusões podem ser extraídas da análise da tabela 7 , que retrata a evolução da disponibilidade de proteínas. Considerando novamente os dados de disponibilidade per capita/dia, notamos que o valor relativo a 1980 é apenas levemente superado em 1991. Os dados referentes a 1986 e 1992, são muito próximos da disponibilidade em 1980. As oscilações verificadas não apresentam tendência de crescimento, ou seja, como no caso das calorias, a evidência é de que o consumo per capita de proteínas também esta estagnado.

Avaliando as informações até aqui apresentadas, tanto do lado da produção quanto do consumo (via disponibilidade per capita), podemos concluir que, embora não sendo identificados estrangulamentos de oferta, esta atende à demanda 
de alimentos reprimida e estagnada. Ou seja, o equilíbrio tem ocorrido em níveis baixos de consumo, dado o perfil da distribuição de rendas. Esta constatação é relevante porque a volta ao crescimento econômico pode implicar graves problemas para o abastecimento alimentar. Mais ainda, sem resposta adequada da oferta, o esforço para se obter melhor situação quanto ao nível e à distribuição de renda pode vir a ser frustrado como efeito do aumento dos preços da alimentação.

Tabela 7

Total geral de proteínas - Brasil, 1970-92

(em bilhão de gramas de proteínas)

\begin{tabular}{llcl}
\hline Ano & $\begin{array}{c}\text { Disponibilidade } \\
\left(\text { O-R) }\left(^{\star}\right)\right.\end{array}$ & \multicolumn{2}{c}{ Disponibilidade per capita } \\
& g/ano & g/dia \\
\hline 1970 & $1.588,68$ & $17.057,04$ & 46,73 \\
1971 & $1.604,99$ & $16.815,01$ & 46,07 \\
1972 & $1.295,18$ & $13.240,75$ & 36,28 \\
1973 & $1.478,56$ & $14.749,55$ & 40,41 \\
1974 & $1.434,89$ & $13.967,42$ & 38,27 \\
1975 & $1.656,38$ & $15.733,13$ & 43,10 \\
1976 & $2.001,96$ & $18.555,36$ & 50,84 \\
1977 & $1.961,54$ & $17.740,60$ & 48,60 \\
1978 & $2.173,83$ & $19.184,63$ & 52,56 \\
1979 & $2.147,15$ & $18.490,44$ & 50,66 \\
1980 & $2.398,73$ & $20.156,95$ & 55,22 \\
1981 & $2.318,87$ & $19.116,09$ & 52,37 \\
1982 & $2.433,78$ & $19.682,70$ & 53,93 \\
1983 & $2.139,98$ & $16.978,31$ & 46,52 \\
1984 & $2.434,74$ & $18.950,33$ & 51,92 \\
1985 & $2.588,09$ & $19.761,69$ & 54,14 \\
1986 & $2.704,74$ & $20.260,51$ & 55,51 \\
1987 & $2.705,09$ & $19.878,67$ & 54,46 \\
1988 & $2.646,74$ & $19.080,84$ & 52,28 \\
1989 & $2.690,46$ & $19.027,96$ & 52,13 \\
1990 & $2.468,59$ & $17.127,53$ & 46,92 \\
1991 & $3.080,50$ & $20.967,54$ & 57,45 \\
1992 & $3.059,93$ & $20.432,38$ & 55,98 \\
\hline
\end{tabular}

(") (O-R)= Oferta (produção, importaçöes) menos retirada (exportaçōes, consumo animal, sementes, perdas) Fonte: CARVALHO, Flávio C. de. Disponibilidade de calorias e proteínas no Brasil: uma reavaliação das estatísticas para a década de oltenta. São Paulo, IEA, 1993.

A respeito deste aspecto, Veiga (1994a) tem alertado para o fato de que os preços dos alimentos, em vários períodos, têm apresentado comportamento de alta superior ao dos demais itens dos índices de custo de vida. Comentando este assunto, o autor evidencia os efeitos nefastos deste comportamento dos preços para as famílias de menor renda, ou seja, para aquelas em que os gastos com alimentação têm maior peso no orçamento familiar. Veiga também evidencia a importância desta constataçáo para o combate à fome no país, uma vez que a 
grande maioria das famílias brasileiras "sobrevive com o equivalente a alguns parcos salários mínimos". Fizemos questão de registrar esta contribuição de Veiga porque ela introduz a questáo da queda dos preços dos alimentos como uma das formas de combate à pobreza, o que novamente questiona a capacidade da oferta.

O exposto leva-nos a indagar sobre os possíveis comportamentos ou perfis da demanda de alimentos e suas implicações para a oferta, questão tratada no próximo tópico.

\section{A agricultura e as alterações no perfil da demanda: previsóes para a oferta}

A bibliografia aqui destacada (Homem de Melo, 1988 e 1991; Embrapa, 1990) trabalha com projeçôes das demandas de produtos agrícolas para diferentes cenários da economia brasileira e atende a diferentes objetivos.

Em Homem de Melo (1991), a meta foi detectar as possibilidades de crescimento da agricultura brasileira, considerando quatro cenários macroeconômicos (baixo crescimento; médio crescimento; alto crescimento; e crescimento social). O trabalho da Embrapa (1990), por sua vez, utilizou as estimativa apresentadas por Homem de Melo (1988) para um estudo sobre planejamento estratégico da instituição e utilizou três cenários (status quo; milagre; e social).

Os cenários macroeconômicos foram construídos com base em diferentes hipóteses sobre as taxas de crescimento da população e da renda, e estimativas sobre as elasticidades renda dos diversos bens agrícolas. Em Homem de Melo (1991), os cenários social e crescimento social incorporam uma hipótese distributiva (crescimento com distribuição de renda), contemplando a possibilidade de atendimento de parte da demanda alimentar reprimida. Na construção desse último cenário o autor chama a atenção para o efeito-graduafão de Yotopoulos (1985), observando que "esse efeito ocorre através do incremento numérico das classes de média-renda e a adoção, pelas famílias que lá chegam, dos hábitos alimentares das famílias que lá já estão". Como resultado dessa graduação, haveria grandes aumentos no consumo de proteínas animais, de legumes/verduras e de frutas. Tal fato também implicaria a ocorrência de significativo aumento nas demandas de cereais e de oleaginosas para raçóes, uma vez que essas demandas são derivadas das quantidades procuradas dos bens de consumo final (Homem de Melo, 1991).

A conclusão principal que podemos extrair dos trabalhos citados é que a volta ao crescimento econômico, principalmente para os casos mais otimistas, abrirá grande espaço para a expansão da agricultura. Essa situação, todavia, implicará a necessidade do setor de, além de superar as suas taxas de crescimento históricas, também crescer em outra direção, ou seja, o perfil da oferta agrícola e 
da pecuária terá de ser alterado. Caso contrário, como já dissemos, o efeito do aumento dos preços tenderá a anular os ganhos de renda. Tal conclusão é especialmente importante para o cenário de crescimento com distribuição, pois as camadas de menor renda verão frustradas as suas possibilidades de consolidar melhores níveis de consumo alimentar.

Com a finalidade de ilustrar o exposto, apresentamos um resumo das informaçóes mais relevantes contidas no trabalho de Homem de Melo (1991).

O autor, discutindo um novo horizonte para o crescimento agrícola, afirma que "dependendo da taxa e do tipo de crescimento agrícola que o Brasil tenha nos próximos dez anos, resultarão taxas bastante diferentes para o crescimento das demandas de produtos alimentares. Em conseqüência, a oferta agrícola terá que sofrer ajustes maiores ou menores dependendo do que ocorra com as variáveis crescimento econômico/distribuiçăo de rendas".

Caracterizando cenários, Homem de Melo assim se expressa: "a) baixo crescimento: crescimento de $2,5 \%-3,0 \%$ do PIB e incremento populacional de $1,6 \%$ (média dos próximos dez anos); b) médio crescimento: $4,5 \%$ para o crescimento do PIB e mesmo incremento populacional; c) alto crescimento: $7,5 \%$ de crescimento do PIB e mesmo aumento populacional; d) crescimento social: 6,5\% para o aumento do PIB, melhor distribuição da renda e mesmo crescimento populacional". Com relação à demanda externa, $o$ autor assume taxas maiores nos dois últimos cenários.

Tabela 8

Taxas anuais médias de crescimento do consumo de alimentos nos quatro cenários da economia

(em \% ao ano)

\begin{tabular}{|c|c|c|c|c|}
\hline \multirow{2}{*}{ Produtos } & \multicolumn{4}{|c|}{ Cenários } \\
\hline & $\begin{array}{l}\text { Baixo } \\
\text { Cresc. }\end{array}$ & $\begin{array}{l}\text { Médio } \\
\text { Cresc. }\end{array}$ & $\begin{array}{l}\text { Alto } \\
\text { Cresc. }\end{array}$ & $\begin{array}{l}\text { Cresc. } \\
\text { Social }\end{array}$ \\
\hline Arroz & 1,60 & 1,60 & 1,60 & 1,26 \\
\hline Feijão & 1,50 & 1,26 & 1,04 & $0,40^{\prime}$ \\
\hline Milho & 2,34 & 4,01 & 5,27 & 5,93 \\
\hline Soja & 2,34 & 4,01 & 5,27 & 6,35 \\
\hline Trigo & 2,08 & 3,08 & 3,91 & 3,86 \\
\hline GRÃOS-TOTAL & 2,18 & 3,50 & 4,53 & 4,99 \\
\hline Batata & 2,31 & 3,71 & 4,83 & 3,99 \\
\hline Mandioca & 1,23 & 0,30 & $-0,60$ & 1,16 \\
\hline Açúcar & 1,90 & 2,54 & 3,09 & 2,63 \\
\hline Carne Bovina & 2,62 & 4,51 & 5,98 & 6,78 \\
\hline Carne Frango & 2,34 & 3,79 & 4,95 & 5,57 \\
\hline Carne Suína & 1,90 & 2,54 & 3,09 & 3,33 \\
\hline Ovos & 2,13 & 3,20 & 4,08 & 4,61 \\
\hline Leite & 2,73 & 4,78 & 6,37 & 7,26 \\
\hline Café & 1,89 & 2,54 & 3,09 & 3,05 \\
\hline Frutas & 2,48 & 5,27 & 7,41 & 8,44 \\
\hline Legumes/Nerduras & 2,19 & 3,52 & 4,69 & 5,35 \\
\hline
\end{tabular}


Tabela 9

Prōjeções de consumo de alimentos em dez anos em quatro cenários de crescimento da economia

$(1.000 t)^{\star}$

\begin{tabular}{|c|c|c|c|c|}
\hline \multirow[b]{2}{*}{ Produtos } & \multicolumn{4}{|c|}{ Cenários } \\
\hline & $\begin{array}{l}\text { Baixo } \\
\text { Cresc. }\end{array}$ & $\begin{array}{l}\text { Médio } \\
\text { Cresc. }\end{array}$ & $\begin{array}{l}\text { Alto } \\
\text { Cresc. }\end{array}$ & $\begin{array}{l}\text { Cresc. } \\
\text { Social }\end{array}$ \\
\hline Arroz & 12.006 & 12.006 & 12.006 & $11.565 t$ \\
\hline Feijão & 3.436 & 3.349 & 3.269 & 3.0724 \\
\hline Milho & 35.709 & 42.657 & 48.697 & 52.164 - \\
\hline Soja & 28.222 & 33.714 & 38.486 & 41.227 - \\
\hline Trigo & 7.521 & 8.376 & 9.145 & 9.098 \\
\hline GRÃOS-TOTAL & 86.894 & 100.102 & 111.603 & 117.126 \\
\hline Batata & 2.980 & 3.461 & 3.897 & 3.565 \\
\hline Mandioca & 29.800 & 26.933 & 24.378 & $22.908_{4}$ \\
\hline Açúcar & 11.020 & 11.809 & 12.517 & 11.915 \\
\hline Carne Bovina & 3.658 & 4.469 & 5.212 & 5.663 \\
\hline Came Frango & 2.443 & 2.852 & 3.224 & $3.438-$ \\
\hline Carne Suína & 1.399 & 1.449 & 1.589 & 1.630 \\
\hline Ovos & 2.407 & 2.700 & 2.965 & $3.134 \curvearrowleft$ \\
\hline Leite & 20.655 & 25.674 & 30.279 & $33.190 \sim$ \\
\hline
\end{tabular}

( ${ }^{*}$ Ovos, milhões de dúzias; leite, milhões de litros.

Os quatro cenários macroeconômicos são ilustrados pelas tabelas 8 e 9 que, respectivamente, apresentam as taxas médias de crescimento previstas para os principais alimentos (próximos dez anos) e os níveis absolutos de consumo previstos para os mesmos alimentos (exceto café, frutas e legumes/verduras).

O texto traz destaque especial para o cenário Crescimento Social, uma vez que este, além de expressar a retomada do crescimento econômico, revela claramente a tendência da "população em realizar uma grande mudança de hábitos de consumo.(...) De uma forte concentração em alguns poucos produtos básicos, tais como arroz, feijão e mandioca, aqueles com predominância calórica, o consumo brasileiro iria, gradativamente, dirigindo-se às proteínas, aos legumes $\mathrm{e}$ às frutas. Em uma posição intermediária ficariam trigo (e derivados), batata, carne suína, café e açúcar”. Ou seja, em tal caso, produtos ora importantes na dieta alimentar (arroz, feijão e mandioca) - responsáveis por $40 \%$ das calorias e por $30 \%$ das proteínas - passariam a ter sua importância reduzida, implicando mudança no perfil da demanda.

Após a análise dos prováveis comportamentos da demanda, o texto discute as necessárias taxas de crescimento da oferta para que o abastecimento seja atendido sem alteração dos preços relativos e/ou declínio das exportações, e/ou aumento das importaçóes. A tabela 10 apresenta as taxas anuais médias de crescimento agrícola essenciais para os quatro cenários. 
Tabela 10

Taxas anuais médias de crescimento agrícola necessárias nos quatro cenários econômicos considerados para os próximos

(em \%/ano)

\begin{tabular}{lccccc} 
Produtos & Década 80 & \multicolumn{4}{c}{ Cenários } \\
& & $\begin{array}{c}\text { Baixo } \\
\text { Cresc. }\end{array}$ & $\begin{array}{c}\text { Médio } \\
\text { Cresc. }\end{array}$ & $\begin{array}{c}\text { Alto } \\
\text { Cresc. }\end{array}$ & $\begin{array}{c}\text { Crescim. } \\
\text { Social }\end{array}$ \\
\hline Lavoura-Grãos & 3,6 & 2,1 & 3,5 & 4,5 & 5,0 \\
Lavouras-Total & 3,1 & 2,0 & 3,0 & 3,9 & 4,2 \\
Produtos Animais & 3,4 & 2,5 & 5,1 & 6,4 & 6,9 \\
Agropecuária Total & 3,2 & 2,2 & 3,8 & 4,9 & 5,3 \\
\hline
\end{tabular}

Fonte: Tabela 4 para os dados de quantidades: índices Laspeyres com ponderações de 1988.

As principais observaçóes que a tabela sugere referem-se às taxas de crescimento da agropecuária para os três últimos cenários serem maiores que o desempenho apresentado na década de 80 ; às taxas de crescimento necessárias para os produtos animais predominarem sobre as demais, cabendo realçar que para o caso de crescimento social, a taxa necessária é o dobro daquela verificada nos anos 80 ; às taxas necessárias para as lavouras (e dos grãos), para os dois últimos cenários, apresentarem níveis significativamente maiores que os verificados na década passada. No caso específico dos grãos (arroz, feijão, milho, soja e trigo), os crescimentos previstos nos dois últimos cenários, são maiores $(4,5 \%$ e $5,0 \%)$ que a taxa verificada nos anos $80(3,6 \%)$.

Considerando-se as tabelas 8 e 9, podemos verificar que para o caso das melhores hipóteses de crescimento, a agricultura nacional teria de alterar o seu perfil de oferta, "na direção dos produtos animais e dos grãos necessários em suas produçóes. Isso, além dos crescimentos, ainda no cenário social, de $8,4 \%$ ao ano na oferta de frutas e de $5,3 \%$ ao ano na de legumes/verduras".

Em resumo, o trabalho de Homem de Melo (1991) - o texto da Embrapa (1990) leva à mesma conclusão - evidencia que, para os melhores cenários macroeconômicos, a agricultura terá significativas possibilidades de expansão e forte necessidade de alterar a composição da produção. Tal fato - alterar o perfil da oferta - é mais significativo para o caso desejável de crescimento com distribuição de renda. Trata-se de um imperativo, sob pena de que a possível tentativa de crescer com distribuição venha a se perder.

\section{Conclusão geral e algumas observaçôes finais}

O exposto anteriormente permite-nos concluir que, frente as previsões mais 
otimistas sobre a demanda, o equilíbrio entre oferta e procura de alimentos no Brasil é precário. Conseqüentemente, tornam-se necessárias políticas públicas que visem a possibilitar a transformação do perfil da oferta e melhorar a eficácia produtiva.

Estas políticas abrangem um amplo leque de problemas (Seplan, 1994) e medidas, cabendo aqui destacar a necessidade de uma política de fortes investimentos em pesquisa agropecuária, educação e extensão rural; a revisão da carga tributária incidente sobre os produtos alimentares; o melhoramento da infraestrutura de transporte e energia; a correção das imperfeiçóes no sistema de comercialização; a redução das perdas na agricultura, abrangendo toda a cadeia produtiva e o consumo; as medidas específicas visando à produção de alimentos (preços mínimos, apoio à agricultura familiar). Em resumo, um conjunto de medidas coerentes que objetive aumentar a eficiência produtiva e apoiar a produção de alimentos.

É bem verdade que as medidas relacionadas constam de qualquer discurso sobre a agricultura. Evidentemente, para que deixem de ser genéricas, elas dependem da clara opção governamental pela segurança alimentar, por sua vez, conseqüente de um objetivo maior de política por um modelo de crescimento com distribuição de renda.

Por fim, algumas poucas palavras sobre a questão do acesso a terra e da pequena produção familiar, temas sempre presentes nos debates sobre segurança alimentar.

Além das políticas diretamente voltadas para os problemas específicos da produção $\mathrm{e}$ da comercialização, sẩo também relevantes para a segurança alimentar da população as ações que objetivem integrar mais agricultores ao sistema produtivo, principalmente aqueles que foram e estão sendo excluídos pelo processo de modernização da agricultura.

Resumindo o nosso ponto de vista, exposto em trabalho anterior (Carvatho Filho \& Abramovay), consideramos que o acesso à terra para os produtores familiares tem a função primordial de integrar esses agricultores à sociedade $\mathrm{e}$ ao mercado, garantindo-lhes direitos (entitlements), renda e, conseqüentemente, segurança alimentar. Por outro lado, tal integração fortalece o setor de agricultura familiar, com efeitos positivos sobre a oferta, sem prejuízo da agricultura empresarial. Para nós, uma das funçóes centrais da reforma agrária e de outras medidas que possibilitem o acesso à terra no Brasil de hoje, é ampliar a quantidade de pobres rurais capazes de se afirmar no mercado como agricultores profissionais. 
1 Os trabalhos elaborados no âmbito do Instituto de Estudos Avançados são os seguintes: Quantificação da disponibilidade de alimentos: aspectos metodológicos e evidências para o Brasil na década de oitenta, de Carvalho, F.C. \& Freitas, S.M. In: Agricultura em São Paulo, v. 35, n.1, p. 99-113, 1988; Preços de alimentos e renda do consumidor: algumas alterações, de Vebro C.L.R. e col. In: Informaçōes Económicas, v. 24, n. 5, p. 23-30, maio 1994.

2 Produtos considerados: açúcar, arroz, batata inglesa, batata doce, feijão, mandioca, milho, soja, trigo, aves, bovinos, suínos, leite e ovos.

3 As tabelas 6 e 7 constam de Relatório Preliminar, ainda não divulgado. Agradecemos ao Dr. Flávio C. de Carvalho.pelo acesso aos dados e pela permissão para divulgação.

Referências bibliográficas

ALMEIDA, I.M. População \& produção: perigosos desequilíbrios. Curitiba, Faep/ Boletim Informativo, n. 338, 23-29 maio 1994.

ALVES, E. \& CONTINI, E. A modernização da agricultura brasileira. In: Brandão, A.S.P. (ed.), Os principais problemas da agricultura brasileira: análises e sugestōes, 2. ed. Rio de Janeiro, Ipea, Série Pnpe, 18, 1992.

BARBOSA, F.H. \& SANTIAGO, F.S. Um tema revisitado: a resposta da produção aos preços no Brasil. In: Brandão, A.S.P. (ed.) Os principais problemas da agricultura brasileira: análises e sugestóes, 2. ed. Rio de Janeiro, Ipea, Série Pnpe 18, 1992.

CARVALHO FILHO, José Juliano de \& ABRAMOVAY. Política fundiária: significado, entraves e desempenho. Relatório Final de Pesquisa referente ao projeto Pnud/ SAE BRA/92/030. São Paulo 15 fev. 1993.

EMBRAPA. Cenários para a pesquisa agropecuária: aspectos técnicos e aplicafão na Embrapa. Brasília, Embrapa, SEA, doc.2, 1989.

- Cenários para a pesquisa agropecuária: aspectos teóricos e aplicacão na Embrapa. Brasília, Embrapa/SEA, doc. 2, 1990.

GOLDIN, I. \& RESENDE, G.C. A agricultura brasileira na década de 80: crescimento numa economia em crise. Rio de Janeiro, Ipea, 1993, p. 16.

HOFFMANN, R. A diminuição do consumo do feijão no Brasil. - A inseguranga alimentar no Brasil, abr. 1994, p 9-10.

HOMEM DE MELO, F. A questẫo da produção e do abastecimento alimentar no Brasil. Brasília, Ipea/Iplan/Pnud, 1988. 
- Agricultura brasileira: um novo horizonte de crescimento. Estudos Econômicos, v. 21 . n. 3, p. 299-317, set./dez. 1991.

- O futuro da agricultura brasileira: desafios e problemas. Fórum Cargill de Debates. - O Futuro Agricola Brasileiro, Campinas, Fundação Cargill, 1994.

PASTORE, A.C. A resposta da produção aos preços no Brasil. Boletim 55, FCEA-USP, 1968.

SEPLAN-PR. Reflexões sobre os problemas da agricultura brasileira (versão preliminar). Brasília, jun. 1994.

VEIGA, J.E. Alimentação e custo de vida. São Paulo, Informaçôes Fipe n. 60, jan. 1994, p. 23-26.

. O caminho (esquecido) do combate à fome. São Paulo, Folha de S. Paulo, 20 abr. 1994.

YOTOPOULOS, P.A. Middle-income classes and food crises: the new food-feed competition. Economic Development and Cultural Change, v. 33, n. 3, p. 463-483, 1985.

José Juliano de Carvalho Filho é professor da Faculdade de Economia, Administração e Contabilidade da USP.

Texto apresentado no seminário Pobreza, fome e desnutrição no Brasil realizado em 2 de dezembro de 1994 no IEA-USP. 